\title{
Pengaruh Campuran High Purity Metanol (HPM) -Solar Menggunakan Sistem EGR terhadap Performa dan Emisi Jelaga Pada Mesin Diesel Injeksi Langsung
}

\author{
Aa Setiawan' ${ }^{1)}$, Syaiful ${ }^{2)}$ \\ ${ }^{1}$ Jurusan Teknik Pendingin dan Tata Udara, Politeknik Negeri Indramayu \\ Jl. Lohbener Lama No. 08 Kec. Lobener Kab. Indramayu 45251 \\ ${ }^{2}$ Jurusan Teknik Mesin, Fakultas Teknik, Universitas Diponegoro \\ Jl. Prof. H. Soedarto, SH, Tembalang, Semarang 50239 \\ Email : atila_waone@yahoo.co.id
}

\begin{abstract}
The aim of this study is to experimentally investigate the effects of HPM and diesel fuel blends on the performance and emissions of a diesel engine. The considered parameters are torque, brake power, specific fuel consumption and thermal efficiency as well as smoke opacity. A four-stroke water cooled direct injection (DI) diesel engine with naturally aspirated, Isuzu 4JB1, combined with cooled EGR system was used for conducting test with HPM-diesel blended fuels with ratio 0/100, 5/95, 10/90, and 15/85 on volume basis at the variation of engine loads in the range of $25 \%$ to $100 \%$ with $25 \%$ interval at $2000 \mathrm{rpm}$. Each load was given EGR rate 0\%, and $100 \%$.The results showedthat compared with neat diesel, theengine brake power decreases 4,69\% by using fuel blends, where the brake power decreases by increasing the HPM volume fraction.It can be also seen that BTE increase 14,7\%, while BSFC decrease 10,29\%. On emission, soot emission decreases significantly $59,32 \%$ by blending HPM with diesel, where increasing HPM volume fractions in the blends tends to lower the soot emission. Based on this research,HPM15 will give performance near to diesel and highest soot emission decrease, while HPM5 give the best results on BSFC, and BTE.
\end{abstract}

Keyword: HPM, Cold EGR, Diesel Engine, Smoke Opacity

\begin{abstract}
Abstrak
Penelitian ini mempelajari pengaruh campuran HPM dan solar terhadap performa dan penurunan emisi jelaga pada mesin diesel. Parameter yang menjadi pertimbangan adalah torsi, daya, konsumsi bahan bakar spesifik dan efisiensi termal serta kepekatan asap. Sebuah mesin diesel injeksi langsung, 4 langkah, berpendingin air, naturally aspirated, Isuzu 4JB1, yang dilengkapi dengan sistem cooled-EGR digunakan pada penelitian ini dengan menggunakan campuran bahan bakar HPM-solar dengan rasio 0/100 5/95, 10/90, dan $15 / 85$ berbasis volume dengan melakukan variasi pembebanan dari $25 \%$ sampai dengan $100 \%$ dengan interval 25\%, pada putaran mesin konstan 2000 rpm. Pada setiap pembebanan, EGR divariasikan dengan laju EGR 0\%, dan 100\%.Hasil penelitian menunjukkan bahwa, dibandingkan dengan solar $100 \%$, pemakaian campuran bahan bakar menurunkan daya mesin sebesar 4,69\%, dimana daya semakin menurun seiring meningkatnya kandungan HPM. Diamati juga bahwa pemakaian campuran bahan bakar akan meningkatkan BTE sebesar 14,7\%, sedangkan nilai BSFC,mengalami penurunan sebesar 10,29\%. Pada sisi emisi, penggunaan campuran bahan bakar menurunkan emisi jelaga sebesar 59,32\%dimana emisi jelaga menurun seiring dengan bertambahnya HPM dalam campuran bahan bakar. Berdasarkan hasil penelitian, kandungan H85M15 menghasilkan torsi dan daya yang mendekati diesel serta penurunan emisi jelaga tertinggi, sementaraH95M5 memberikan hasil terbaik dari sisi BSFC dan BTE.
\end{abstract}

Kata kunci: Metanol Kadar Tinggi, EGR-Dingin, Mesin Diesel, Kepekatan Asap

\section{PENDAHULUAN}

Mesin diesel banyak digunakan karena memiliki beberapa keunggulan antara lain sistem pembakarannya menggunakan compression-ignition yang tidak memerlukan busi. Sistem ini memungkinkan tercapainya tekanan awal yang tinggi sebelum terjadi proses pembakaran. Hal ini akan meningkatkan efisiensi termal dibandingkan sistem yang lain [1]. Keunggulan yang lain adalah fleksibilitas jenis bahan bakaryang digunakan. Karena pembakaran yang terjadi tidak memerlukan pengontrolan bunga api, maka berbagai jenis bahan bakar bisa digunakan.Namun dibandingkan dengan mesin bensin, mesin diesel dianggap lebih banyak memberikan kontribusi dalam pencemaran udara yaitu Emisi jelaga (soot) dan Nitrogen Oxide 
$\left(\mathrm{NO}_{\mathrm{x}}\right)$.Emisi jelaga merupakan masalah utama motor diesel karena sistem pembakaran dilakukan dengan menyemprotkan bahan bakar di akhir langkah kompresi yang dapat berakibat pada tidak tercampurnya bahan bakar dan udara secara menyeluruh saat pembakaran terjadi. Jelaga terbentuk karena adanya $\mathrm{CO}_{2}$ pada temperatur tinggi lebih dari $1500 \mathrm{~K}$ dengan kondisi kekurangan oksigen [2].

Low Purity Methanol (LPM) dapat dipertimbangkan sebagai bahan bakar campuran untuk mesin diesel karena telah terbukti dapat menurunkan emisi jelaga secara drastis, namun menurunkan performa mesin [3].Ada beberapa kelebihan dari metanol antara lain metanol mempunyai viskositas yang lebih rendah dibanding dengan minyak diesel sehingga lebih mudah diinjeksi, diatomisasi dan dicampur dengan udara[4]. Bahan bakar tersebut dapat digunakan secara murni maupun dicampur dengan bahan bakar lain.

Mesindieselbiasanyadicirikandengankonsumsiba han bakarrendahdan penghasil emisiCO yang rendah.Namun,emisiNOxdarimesindieselmasihtetapti nggi. Nitrogen Oksida dihasilkan akibat adanya $\mathrm{N}_{2}$ (Nitrogen) dalam campuran udara dan bahan bakar pada tekanan dan suhu yang tinggi di ruang bakar yaitu antara $1800-2000^{\circ}$ C.Ada 3 faktor utama penyebab terbentuknya NOx yaitu temperatur pembakaran, ketersediaan Oksigen dan waktu tunggu pada zona temperatur [5]. EGR (Exhaust Gas Recirculation) menjadi salah satu cara untuk mereduksi tingginya emisi $\mathrm{NO}_{\mathrm{x}}$ yang ditimbulkan mesin diesel karena dapat menurunkan temperatur di ruang bakar[6].Metode ini dilakukan dengan mensirkulasikan sebagian gas buang ke dalam intake manifold yang kemudian bercampur dengan udara sebelum masuk ke dalam ruang bakar.Telah dilakukan penelitian bagaimana suatu cooled EGR (Exaust Gas Recirculation) dapat menurunkan NOx[7].

Dari pemaparan di atas, penggunaan Low Purity Methanol (LPM) terbukti dapat menurunkan emisi jelaga, namun belum dapat mempertahankan performa mesin. Dalam penelitian ini, akan dilakukan eksperimen penggunaan High Purity Methanol (HPM) sebagai campuran bahan bakar dan cooled EGR untuk mengetahui pengaruhnya terhadap emisi jelaga dan performa mesin.

\section{METODE DAN PERALATAN}

Bahan bakar yang digunakan pada penelitian ini adalah bakar High Purity Metanol (HPM) dan Solar (S).Bahan bakar solar diproduksi oleh PT. Pertamina, Tbk. Metanol dengan tingkat kemurnian99,9\% dibeli dari toko kimia, Semarang. Karakteristik utama bahan bakar tersebut ditunjukkan pada tabel 1 . persentase volume metanol yang diuji adalah 5\%, $10 \%$, dan $15 \%$ dari volume solar, secara berurutan disebut, HPM5S95, HPM10S90 dan
HPM15S85.Pencampuran bahan bakar dipersiapkan sebelum dimulainya eksperimen untuk memastikan bahwacampuran tersebut homogen. Sebuah pengaduk digunakan saat pencampuran bahan bakar tersebut.

Tabel 1 Karakteristik bahan bakar ${ }^{(1)}$ Dirjen Migas, 2006; ${ }^{(2)}$ BPPT, 2014)

\begin{tabular}{clccc}
\hline NO & KARAKTERISTIK & SATUAN & $\begin{array}{c}\text { SOLAR } \\
\text { EURO II }\end{array}$ & HPM $^{2)}$ \\
\hline $\mathbf{1}$ & Angka Setana & - & 48 & 4,8 \\
\hline $\mathbf{2}$ & Kadar Air & $\% \mathrm{v}$ & 0,05 & 0,05 \\
\hline $\mathbf{3}$ & $\begin{array}{l}\text { Viscositas Kinematik (pada } \\
\left.\text { Suhu } 40{ }^{\circ} \mathrm{C}\right)\end{array}$ & $\mathrm{mPa} . \mathrm{s}$ & $2,0-5,0$ & 0,6 \\
\hline $\mathbf{4}$ & Densitas (pada suhu $\left.15^{\circ} \mathrm{C}\right)$ & $\mathrm{kg} / \mathrm{m}^{3}$ & 840 & 792 \\
\hline $\mathbf{5}$ & Nilai Kalor & $\mathrm{MJ} / \mathrm{kg}$ & 45,21 & 22,08 \\
\hline $\mathbf{6}$ & Titik Nyala & ${ }^{\circ} \mathrm{C}$ & 60 & 13 \\
\hline
\end{tabular}

Eksperimen dilakukan dengan mesin diesel injeksi langsung 4 silinder yang spesifikasinya dijelaskan pada tabel 2. Pengujian dilakukan pada putaran stasioner $2000 \mathrm{rpm}$. Level EGR(Exhaust Gas Recirculation)divariasikan pada OEV (Open EGR Valve) $0 \%$ dan $100 \%$. Masing-masing campuran diberibeban dari $25 \%$ sampai $100 \%$ dengan interval pembebanan $25 \%$. Sebuah dynamometer DYNOmite Land\&Sea tipe waterbreakdigunakan untuk mengukur daya mesin yang nantinya akan digunakan untukmenghitung nilai konsumsi bahan bakar spesifik (BSFC).Smoke Opacity pada pengujian ini diukur menggunakan alat pengukur emisi Stargas 898 dan Smoke meter OTC 495.

Tabel 2. Spesifikasi mesin diesel

\begin{tabular}{ll}
\hline Model of engine type & $\begin{array}{l}\text { Isuzu 4JB1 } \\
4 \text { cylinder, } 4 \text { cycle, OHV, vertical in-line, } \\
\text { direct injection }\end{array}$ \\
Cylinder number & 4 \\
Cylinder bore & $93 \mathrm{~mm}$ \\
Cylinder stroke & $102 \mathrm{~mm}$ \\
Compression ratio & $18.2: 1$ \\
Compression pressure & $31 \mathrm{~kg} / \mathrm{cm}^{2}$ \\
Total cylinder volume & $2771 \mathrm{cc}^{2}$ \\
Maximum power & $52.2 \mathrm{~kW}$ at $3000 \mathrm{rpm}$ \\
Maximum torque & $178.96 \mathrm{Nm}$ at $2000 \mathrm{rpm}$ \\
\hline
\end{tabular}

Peralatan percobaan disusun seperti pada gambar 1. Campuran bahan bakar yang telah dipersiapkan sesuai dengan persentase campurannya dialirkan ke mesin diesel. Kemudian aliran bahan bakar diukur untuk mengetahui konsumsi bahan bakar tersebut. Saat mesin diesel bekerja, pembebanan dilakukan dengan beberapa variasi beban yang diukur dengan menggunakan dynamometer. Hal ini dilakukan dalam rangka untuk mengukur torsi dan daya pengereman. Dilainsisi, pada sisi knalpot (exhaust) yang telah dihubungkan dengan EGR juga diatur variasi valvemenuju EGR nya. Pengolahan data akan dilakukan dengan bantuan software MS. Excel 2007 dan software Origin 8, serta 
hasilnya akan dipresentasikan dalam bentuk grafik. Proses pengujian yang dilakukan pada penelitian ini mengacu pada ASTMD6751 [8]

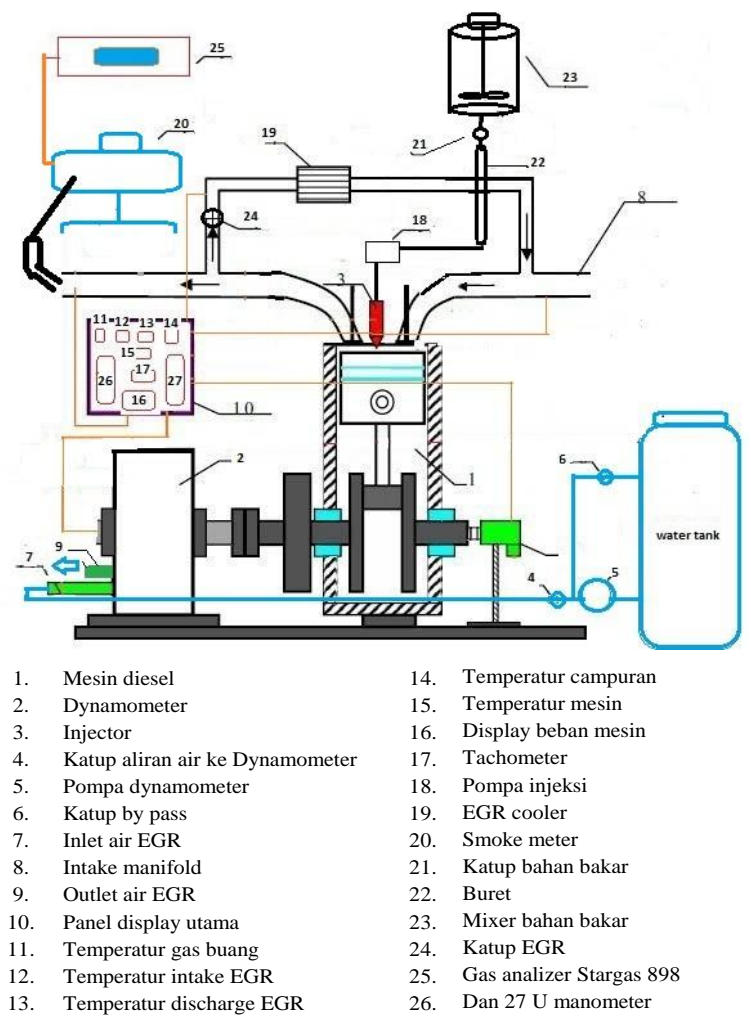

Gambar 1. Experimental set up

\section{HASIL DAN PEMBAHASAN}

Penelitian ini dilakukan dengan metode eksperimen murni yang bertujuan untuk mencaripengaruh HPM terhadap performa mesindan emisi jelaga pada mesin diesel injeksi langsung. Penelitian dilakukan di Laboratorium Mekanika Fluida Teknik Mesin, Universitas Diponegoro, Semarang. Hasil pengujian dari beberapa macam campuran bahan bakar dengan OEV (Open EGR Valve) 0\%dan 100\% masing-masing dipresentasikan pada Gambar 2 sampai dengan 11.

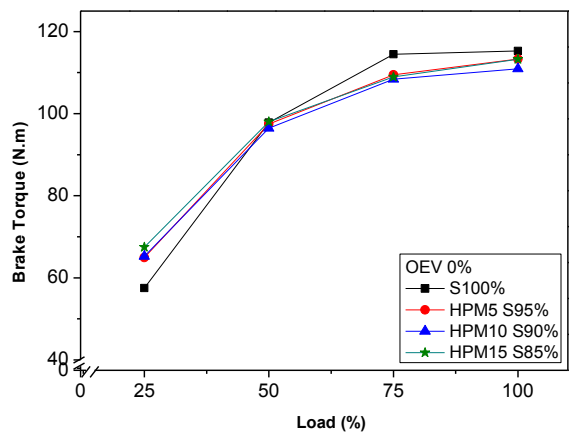

Gambar 2. Torsi untuk berbagai macam campuran bahan bakar dengan OEV 0\%

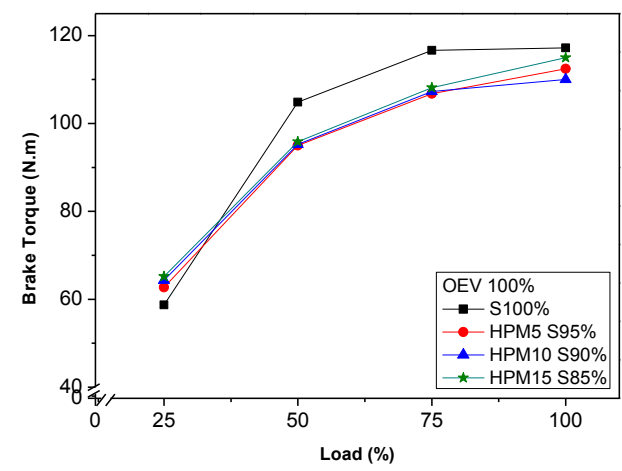

Gambar 3. Torsi untuk berbagai macam campuran bahan bakar dengan OEV 100\%

Berdasarkan Gambar 2 dan 3, pemakaian bahan bakar campuran menghasilkan torsi lebih rendah dibandingkan dengan solar murni karena rendahnya nilai kalor dari bahan bakar campuran yang berpengaruh terhadap karakteristik pembakaran [9].Semakin besar kandungan methanol dalam bahan bakar, torsi yang dihasilkan cenderung menurun karena rendahnya nilai kalor dari methanol[3].

Gambar 2.menunjukkan pengaruh bahan bakar terhadap brake torque pada mesin diesel tanpa EGR (OEV 0\%). Nilai torsi menurun dengan penggunaan bahan bakar campuran kecuali pada beban 25\%, bahan bakar HPM15S85 mengalami peningkatan sebesar $17,33 \%$ terhadap S100 pada beban yang sama.Penurunan torsi tertinggi terjadi pada HPM10S90 saat beban $75 \%$ yaitu sebesar $5,29 \%$ terhadap S100 pada beban yang sama. Nilai torsi tertinggi terjadi pada bahan bakar S100 saat beban penuh yaitu 115,29 Nm.Ketika menggunakan bahan bakar campuran, nilai torsi tertinggi pada HPM5S95 pada beban penuh sebesar $113,33 \mathrm{Nm}$.

Pada OEV $100 \%$, nilai torsi menurun dengan penggunaan bahan bakar campuran kecuali pada beban 25\%, bahan bakar HPM15S85 mengalami peningkatan sebesar $11,09 \%$ terhadap S100 pada beban yang sama. Penurunan torsi tertinggi terjadi pada HPM10S90 saat beban 50\% yaitu sebesar $9,43 \%$ terhadap S100 pada beban yang sama. Nilai torsi tertinggi terjadi pada bahan bakar S100 saat beban penuh yaitu $117,20 \mathrm{Nm}$. Ketika menggunakan bahan bakar campuran, nilai torsi tertinggi pada HPM15S85 pada beban penuh sebesar 114,97 Nm. 


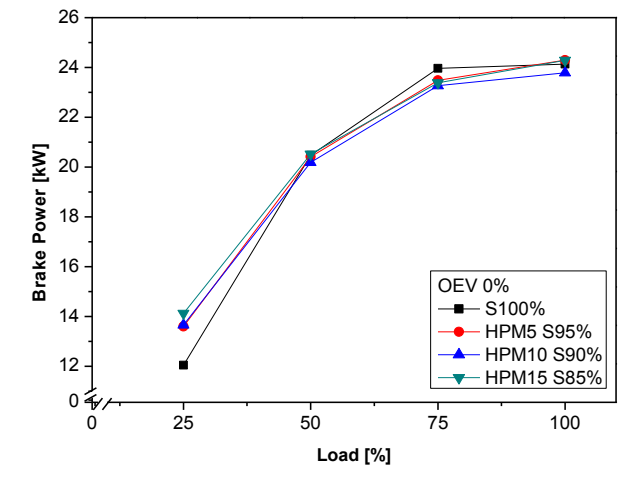

Gambar 4. Brake power untuk berbagai macam campuran bahan bakar dengan OEV $0 \%$

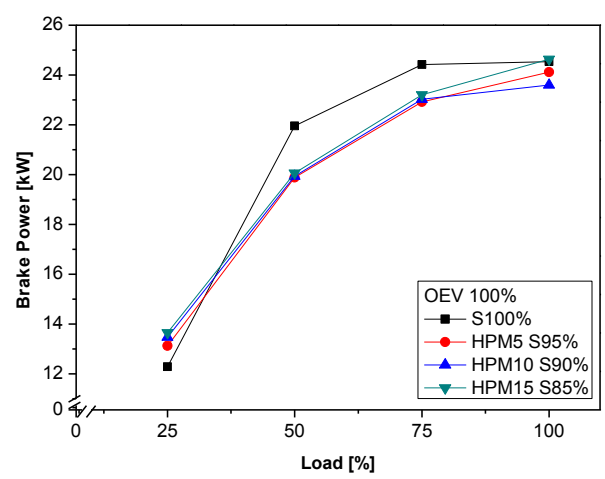

Gambar 5. Brake power untuk berbagai macam campuran bahan bakar dengan OEV 100\%

Qi dkk.,(2010) mengungkapkan semakin besar kandungan LPM dalam bahan bakar, daya yang dihasilkan cenderung menurun karena rendahnya nilai kalor dari LPM. Gambar 4 dan 5 menyajikan pengaruh prosentase HPM terhadap brake power.

Pada gambar 5 menunjukkan pengaruh prosentase HPM terhadap brake power pada mesin diesel tanpa EGR. Pada beban 25\%, campuran HPM15S85 terlihat memiliki nilai brake power lebih tinggi 11,4\% dari S100 serta 3,9\% dari HPM10S90 dan HPM5S95. Namun pada beban $100 \%$, campuran HPM10S90 memiliki nilai brake power lebih rendah 2,4\% dari S100.

Pada OEV 100\% dan beban penuh, prosentase campuran H15D85 menghasilkan brake power lebih randah 0,4\% serta lebih tinggi dibanding HPM5S95 dan HPM10S90 yaitu sebesar 24,638 kW.

Zhu dkk., (2010) mengungkapkan, semakin tinggi konsentrasi metanol pada campuran bahan bakar mengakibatkan nilai BSFC meningkat karena nilai kalor yang lebih rendah dari metanol dibandingkan diesel.

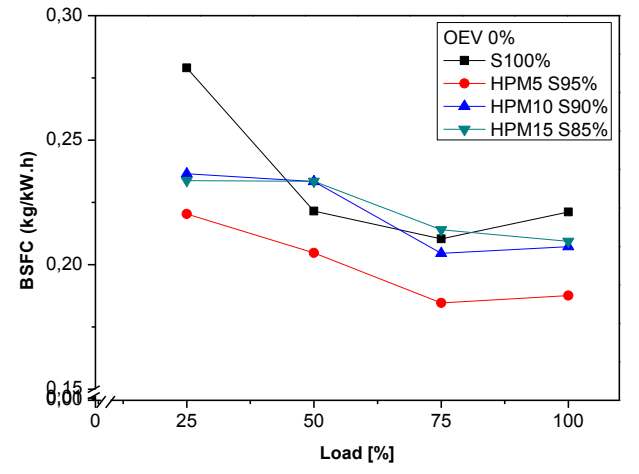

Gambar 6. BSFC untuk berbagai macam campuran bahan bakar dengan OEV $0 \%$

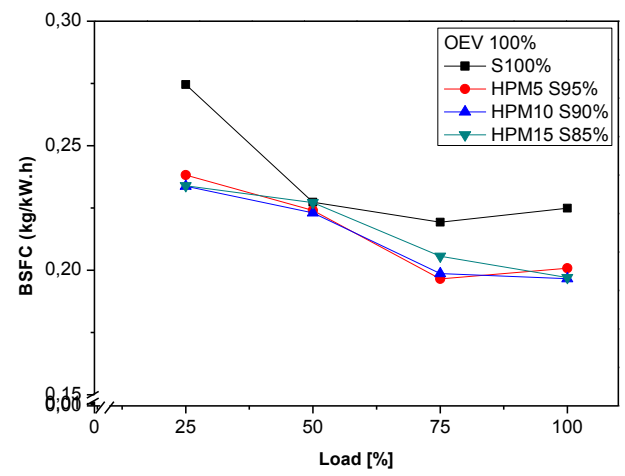

Gambar 7. BSFC untuk berbagai macam campuran bahan bakar dengan OEV 100\%

Gambar 6 dan 7, menyajikan penguruh campuran HPM terhadap BSFC dengan OEV 0\% dan $100 \%$ Pada setiap beban, tingginya prosentase campuran HPM menghasilkan nilai BSFC menjadi lebih tinggi. Gambar 4 menunjukkan pengaruh yang berbeda. Pada OEV 100\% dan beban penuh, peningkatan prosentase campuran HPM menghasilkan penurunan nilai BSFC. Hal ini dikarenakan pengaruh tingginya kandungan oksigen dan meningkatkan karakteristik semprotan akibat rendahnya viskositas yang mengakibatkan tingginya laju pembakaran sehingga meningkatkan kualitas pembakaran [9]. Nilai BSFC HPM10S90 dan HPM15S95 lebih rendah 2\% dari HPM5S95, sementara HPM15S95 lebih rendah 14,1\% dari S100. Nilai BSFC terendah terjadi pada HPM10S90 dan HPM15S95 sebesar 0,196 kg/kW.h. 


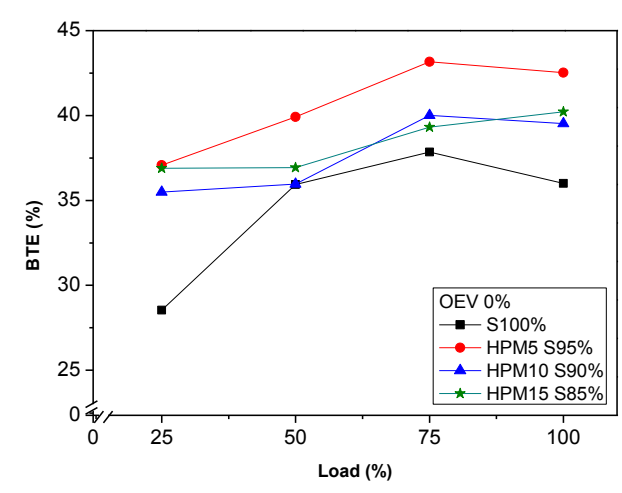

Gambar 8. BTEuntuk berbagai macam campuran bahan bakar dengan OEV 0\%

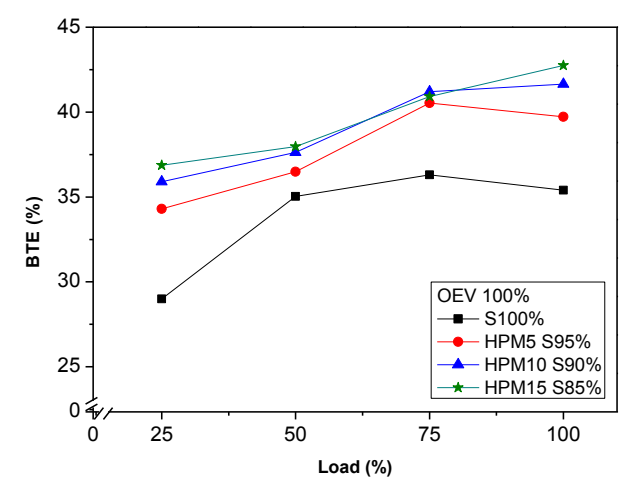

Gambar 9. BTEuntuk berbagai macam campuran bahan bakar dengan OEV100\%

Dari Gambar 8 dan 9 terlihat bahwa BTE meningkat dengan meningkatnya beban.Penggunaan campuran methanol dalam bahan bakar diesel mengakibatkan BTE lebih tinggi dibandingkan dengan solar $100 \%$ karena tingginya kandungan oksigen dalam bahan bakar campuran [10].Semakin besar kandungan metanol dalam campuran bahan bakar, BTE juga cenderung meningkat karena menurunnya aliran massa bahan bakar yang disebabkan kombinasi dari pengaruh tingginya kandungan oksigen dan meningkatnya sifat semprotan akibat rendahnya viskositas yang mengakibatkan kecepatan pembakaran lebih tinggi dari bahan bakar campuran sehingga meningkatkan BTE [11].

Gambar 8 menunjukkan pengaruh bahan bakar terhadap nilai BTE pada mesin diesel tanpa EGR.Pemakaian bahan bakar campuran mengakibatkan BTE lebih tinggi dibandingkan dengan S100.Peningkatan nilai BTE tertinggi terjadi pada HPM5S95 saat beban $25 \%$ sebesar $29,95 \%$ dibandingkan dengan diesel murni. Nilai BTE tertinggi dihasilkan pada beban $75 \%$ ketika memakai HPM5S95 sebesar 43,17\%.

Gambar 9 menunjukkan pemakaian bahan bakar campuran mengakibatkan nilai BTE lebih tinggi dibandingkan dengan S100. Peningkatan nilai BTE tertinggi terjadi pada HPM15S85 saat beban $25 \%$ sebsesar $27,10 \%$ dibandingkan dengan solar $100 \%$. Nilai BTE tertinggi dihasilkan pada beban $100 \%$ ketika memakai HPM15S85 sebesar 42,75\%

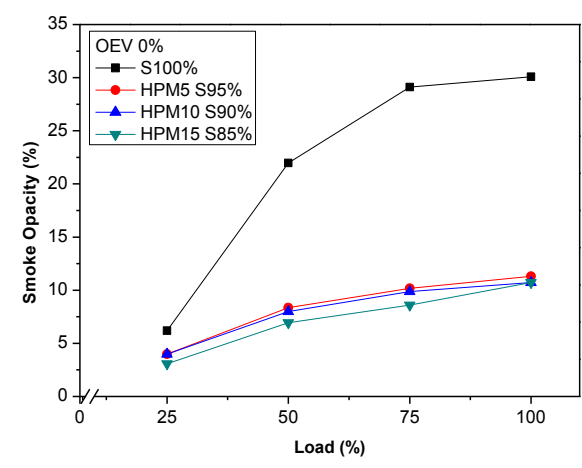

Gambar 10. smoke opacityuntuk berbagai macam campuran bahan bakar dengan OEV $0 \%$

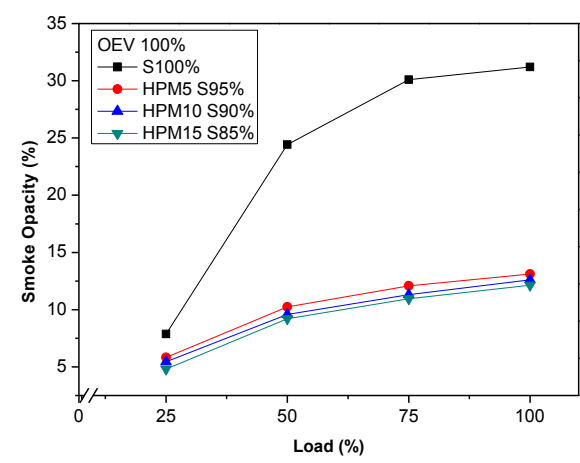

Gambar 11. smoke opacityuntuk berbagai macam campuran bahan bakar dengan OEV 100\%

Dari Gambar 10 dan 11, terlihat bahwasmoke opacity meningkat dengan meningkatnya beban.smoke opacitypada campuran HPM15S85 lebih rendah $157 \%$ dari S100 danterlihat lebih rendah dibandingkan denganHPM5S95 dan HPM10S90. Penurunan smoke opacity ini disebabkan karena kadar Oksigen yang tinggi pada bahan bakar campuran sehingga mendorong terjadinya oksidasi karbon yang mengakibatkan smoke opacity menjadi menurun [12]. Alasan ini diperkuat oleh Heywood (1988) yang mengatakan bahwa emisi soot akan meningkat dengan meningkatnya rasio C/O. Dengan meningkatnya konsentrasi Oksigen pada bahan bakar campuran menyebabkan rasio $\mathrm{C} / \mathrm{O}$ menjadi kecil sehingga akan menurunkan emisi soot yang ditandai dengan menurunnya smoke opacity. Smoke opacity menurun dengan meningkatnya kadar HPM pada bahan bakar karena kandungan Oksigen yang tinggi pada HPM sehingga mendorong terjadinya oksidasi karbon yang mengakibatkan smoke opacity menjadi menurun. Penurunan smoke opacity akibat meningkatnya konsentrasi metanol juga terjadi pada penelitian Cenk Sayin (2010) dan Anand.,dkk. (2011). 


\section{KESIMPULAN}

Berikut ini adalah kesimpulan utama yang didapat pada penelitian mengenai pengaruhmetanol kadar tinggi terhadap performa mesin dan emisi jelaga pada mesin diesel injeksi langsung dengan sistemcooledEGR:

1. Secara keseluruhan, nilai brake torque dan brake power yang dihasilkan bahan bakar campuran cenderung lebih rendah dibandingkan dengan diesel namun terjadi peningkatan pada pembebanan yang rendah. HPM15S85 memiliki nilai rata-rata penurunan terendah atau paling mendekati D100 yaitu $4,69 \%$

2. HPM5S95 merupakan campuran bahan bakar terbaik dengan nilai rata-rata penurunan BSFC tertinggi yaitu sebesar 10,29\%.

3. HPM5S95 merupakan campuran bahan bakar terbaik dengan nilai rata-rata peningkatan BTE sebesar $14,76 \%$.

4. HPM15S85 merupakancampuran bahan bakar terbaik untuk menurunkan smoke opacity.

\section{DAFTAR PUSTAKA}

[1] Gomma, M., Alimin, A.J., Kamarudin, K.A., 2010, "Trade off Between NOx, Soot and EGR rates for IDI Diesel Engine Fuelled with JB5," World Academy of Science, Engineering and Technology, 38, pp. 522-527.

[2] Teini, P.D., Darshan, M.A., Karwat, Atreya, A., 2012, "The Effect of $\mathrm{CO}_{2} / \mathrm{H}_{2} \mathrm{O}$ on The Formation of Soot Particles in The Homogeneous Environtment of a Rapid Compression Facility," Elsevier, 159, pp. 10901099.

[3] Qi, D.H., Chen, L.M., Geng, YZH., Bian, $\mathrm{XCH}$., Ren, 2010, "Performance and Combustion Characteristics of Biodiesel-dieselmethanol Blend Fuelled Engine," Elsevier, 87, pp. 1679-1686.

[4] Sayin, C., 2010, "Engine Performance and Exhaust Gas Emissions of Methanol and Ethanol-diesel Blends," Elsevier, 89, pp. 34103415.

[5] Zhu, L., Cheung, C.S., Zhang, W.G., Huang, Z., 2010, "Emissions characteristics of a diesel engine operating on biodiesel and biodiesel blended with ethanol and methanol,", Elsevier, 408, pp. 914-921.

[6] Maiboom, A., Tauzia, X., Hetet, J.F., 2008, "Experimental Study of Various Effect of Exhaust Gas Recirculation (EGR) on Combustion and Emissions of an Automotive Direct Injection Diesel Engine," Elsevier, 33, pp. 22-34.
[7] McKinley (1997) McKinley TL, (1997), Modeling Sulfuric acid condensation in diesel engine EGR coolers, $S A E, 636$.

[8] Yilmaz N, 2012, "Comparative analysis of biodiesel-ethanol-diesel and biodieselmethanol-diesel blends in a diesel engine," Elsevier, 40, pp. 210-213.

[9] Zhiqiang, G., Tianrui, L., Jinlong, D., Rongrong, C., Peijun, X., Xuehong, W., 2011, "Combustion and Emission Characteristics of Blends of Diesel Fuel and Methanol-to-diesel," Elsevier, 90, pp. 1305-1308.

[10] Karabektas, M., Ergen, G., Hosoz, M., 2011, "Effect of the blends containing low ratios of alternative fuels on the performance and emission characteristics of a diesel engine," Elsevier, 04, pp. 36-39.

[11] Anand K, Sharma R.P, Mehta P.S, (2011), Experimental Investigation on Combustion,Performance and Emissions Characteristics of Neat Karanji Biodiesel and ItsMethanol Blends in a Diesel Engine, Elsevier, 35, pp. 533-541.

[12] Syaiful, Stefan Mardikus, M. W. Bae and Kazuo Tsuciya, (2013), Effect of Exaust GasRecirculation on Smoke Emission in a Direct Injection (DI) Diesel Engine Fueled DieselLow Purity Methanol (LPM) Blends, The Seventh international Symposium on Mechanics,Aerospace and Informatics Engineering (ISMAI), ISMAI07-EP-01, pp. 147-151.

[13] Heywood, John B.L., (1988), Internal Combustion Engine Fundamentals, McGrawHill, Inc., NewYork. 